\title{
Metastatic syringoid eccrine carcinoma of the nipple
}

This article was published in the following Dove Press journal:

International Medical Case Reports Journal

10 July 2012

Number of times this article has been viewed

\author{
Pierluigi Ballardini' \\ Guido Margutti' \\ Massimo Pedriali ${ }^{2}$ \\ Patrizia Querzoli \\ 'Department of Internal Medicine, \\ Hospital of the Delta, Lagosanto, \\ ${ }^{2}$ Institute of Pathology, S Anna \\ Hospital, Ferrara, Italy
}

Correspondence: Pierluigi Ballardini Department of Internal Medicine, Hospital of the Delta, via Valle Oppio 2, 44023 Lagosanto, Italy Tel +3905 33723468

Fax +390533723467

Email p.ballardini@ausl.fe.it
Abstract: Syringoid eccrine carcinoma is a very rare skin tumor. Herein we describe a 72-year-old male patient presenting with a syringoid eccrine carcinoma of the nipple with associated axillary lymph node metastases. Surgery associated with adjuvant radiotherapy was performed. To the best of our knowledge, this is the first case of syringoid eccrine carcinoma of the nipple ever reported.

Keywords: syringoid carcinoma, nipple, axillary metastases, radiotherapy

\section{Introduction}

Syringoid eccrine carcinoma (SEC) is an extremely rare malignant adnexal tumor of eccrine origin, first described by Freeman and Wilkemann in 1969. ${ }^{1}$ SEC can occur in the head and neck region and less commonly on the trunk. ${ }^{2}$ Histologically, it is characterized by a syringoma-like tadpole morphology composed of basaloid cells with ductal differentiation within a fibrocollagenous matrix. Perineural and lymphovascular invasion is present. SEC shows an infiltrative growth pattern with deep invasion and often extends into the subcutaneous tissue. These characteristics differentiate this malignancy from syringoma, its benign counterpart. Furthermore, SEC usually recurs locally and can give distant metastases., ${ }^{2,3}$

Immunostaining in SEC is variable, with carcinoembryonic antigen being the most consistently expressed immunohistochemical marker. ${ }^{2}$ Fewer than 50 cases have been reported under the name of SEC and its synonyms. ${ }^{2-20}$ We report a man presenting with an SEC of the nipple associated with axillary lymph node metastases.

\section{Case report}

A 72-year-old Caucasian man came to our attention after the appearance of an ulcerative lesion on the left nipple associated with an increased volume of ipsilateral axillary lymph nodes. The patient underwent ultrasound examination, which showed a retroareolar lesion with irregular contours, a predominantly hypoechoic component, a maximum diameter of $15 \mathrm{~mm}$ and a thickness of $10 \mathrm{~mm}$, and powerful Doppler vascular signals. A needle biopsy of the lesion was performed. The pathologist diagnosed a carcinoma with syringoid features. The patient underwent a radical mastectomy and ipsilateral axillary lymph node dissection.

Histopathological examination showed the presence of a differentiated cutaneous adnexal carcinoma, with syringoid and microcystic morphology, ulcerated and infiltrating subcutaneous tissue with perineural invasion, and a desmoplastic stromal 
reaction (Figures 1-3). Metastases were found in four of the 16 lymph nodes removed. On immunohistochemical staining, the tumor cells expressed carcinoembryonic antigen (Figure 4), cytokeratin (Pan), cytokeratin 7, and p63 protein (Figure 5), and were found to be negative for S100 protein, estrogen, and progesterone receptors. The final diagnosis was SEC with axillary lymph node metastases.

After surgical intervention, the patient underwent a computed tomography scan and positron emission tomography that excluded the presence of distant metastases. Adjuvant radiotherapy at 50 Gray was performed in the axillary and sovraclavear omolateral area. After 26 months of follow-up, clinical and radiological investigation have excluded any tumor relapse.

\section{Discussion}

Primary eccrine carcinomas are rare tumors and make up less than $0.01 \%$ of all skin cancers. ${ }^{4,5} \mathrm{SEC}$ is a malignant adnexal tumor that is more frequently present in the head and neck region but can also be found in the trunk. ${ }^{2}$ Histologically, SEC presents with dilated tubules, sometimes with a tadpole appearance, small neoplastic ducts, solid islands, cellular cords, and keratinizing and nonkeratinizing cysts. Immunostaining is variable, and this variability is believed to stem from the ability of this tumor to differentiate along multiple routes. ${ }^{2}$ The differential diagnosis of SEC includes syringoma, desmoplastic trichoepithelioma, basal cell carcinoma, microcystic adnexal carcinoma, adenoid cystic carcinoma, and infundibular carcinoma.

The molecular pathogenesis of malignant adnexal tumors is not well understood, and the role of ultraviolet irradiation

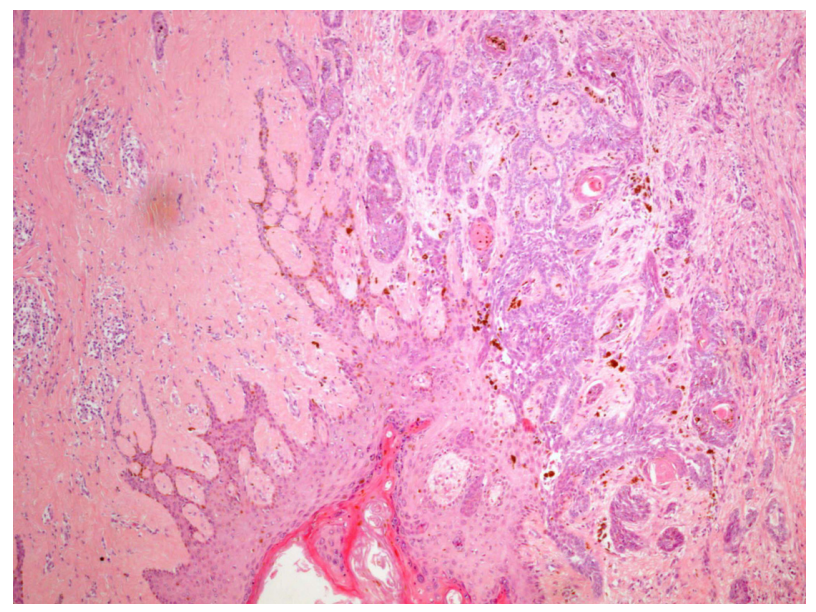

Figure I Solid tumor nests with syringoid morphology showing an infiltrating pattern with angulated profile of epithelial islands.

Note: A desmoplastic stromal reaction is seen on the right side (hematoxylin and eosin, $4 \times)$.

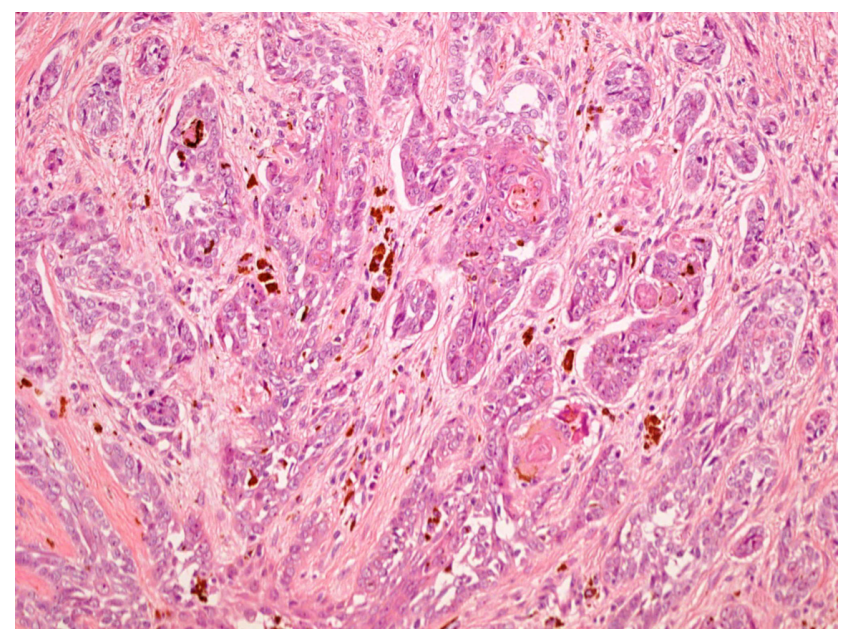

Figure 2 Basaloid cells forming tubular and tadpole-shaped structures (hematoxylin and eosin, 20x).

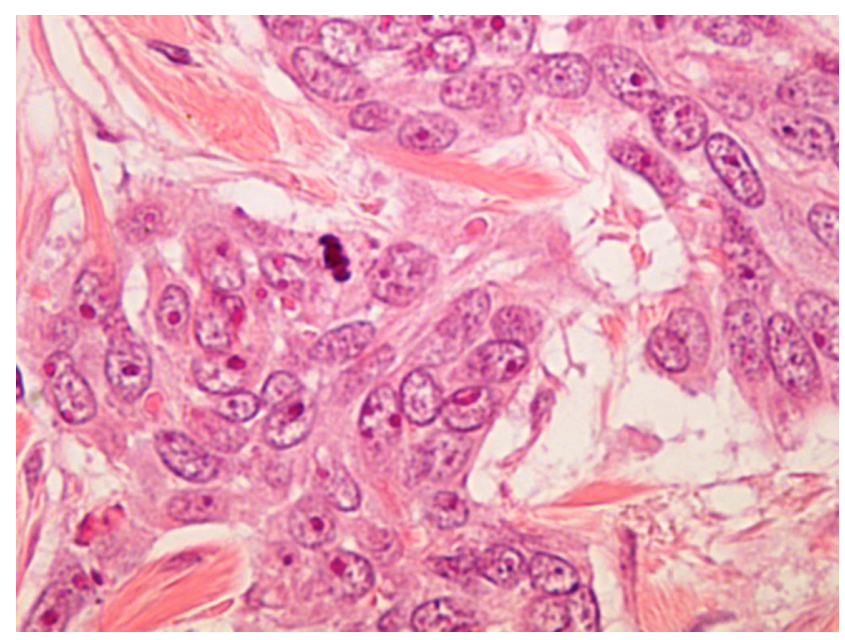

Figure 3 Anaplastic nuclei with prominent nucleoli and mitosis in cancer cells (hematoxylin and eosin, 60x).

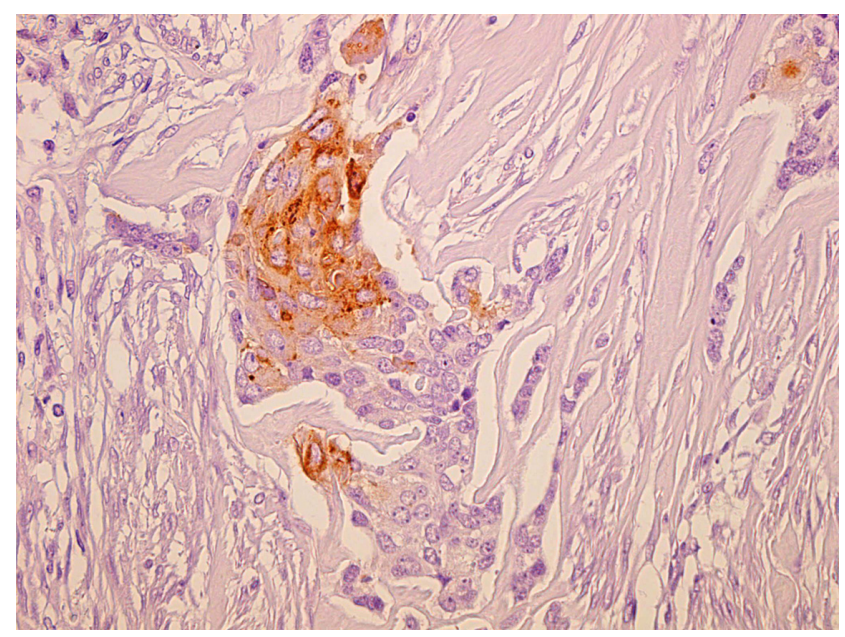

Figure 4 Carcinoembryonic antigen immunohistochemical staining in tumor cells (avidin-biotin method, 20x). 


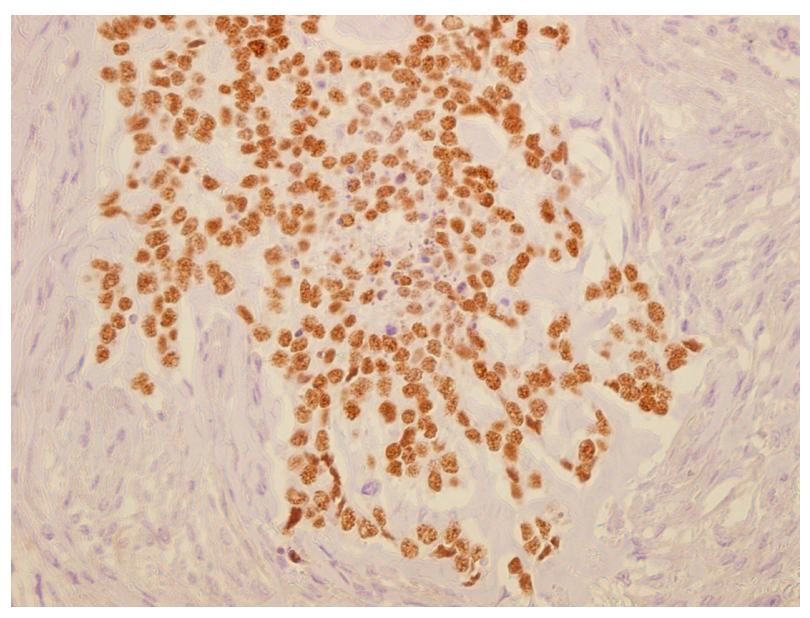

Figure 5 p63 immunohistochemical staining in nuclear tumor cells (avidin-biotin method, 60x).

in the development of these tumors is not clear. In one study, ${ }^{21}$ sweat gland carcinomas were observed to have a low frequency of loss of heterozygosity, and p53 alterations in contrast with the multiple genetic defects normally observed in cutaneous squamous cell carcinomas. This may be partly explained by the relative protection of cutaneous appendages from ultraviolet light and other environmental mutagens. Another study ${ }^{22}$ analyzing p53 mutations in 16 sweat gland carcinomas identified three $\mathrm{G}: \mathrm{C} \rightarrow \mathrm{A}: \mathrm{T}$ transition mutations located in dipyrimidine sequences on an antisense strand, which suggests that ultraviolet light may play a role in the development of these tumors. A further study analyzing 55 cases of sporadic adnexal skin tumors suggested a pathogenetic role of the gene for familial cylindromatosis (CYLD). ${ }^{23}$ Surgical excision with clear margins is the treatment of choice for localized lesions. ${ }^{5,13,17}$ Chemotherapy and radiation therapy have been used for metastatic lesions. In our patient, we have combined adjuvant radiation therapy with surgical treatment, as suggested in a previous study. ${ }^{24}$ Twenty-six months out from completion of therapy, the patient is free from relapse.

\section{Conclusion}

We have reported a case of SEC of the nipple presenting as an ulcerative cutaneous lesion with axillary metastases. To the best of our knowledge, this is the first case of SEC of the nipple which has ever been reported. The presence of lymph node metastases confirmed the malignant potential of this tumor. In our patient, the differential diagnosis also included a primitive breast cancer. Surgery associated with adjuvant radiotherapy seems to be the best choice of treatment for this tumor with regional lymph node metastases.

\section{Disclosure}

No sources of funding were used to assist in preparation of this case report. The authors have no conflicts of interest that are directly relevant to the content of this case report.

\section{References}

1. Freeman RG, Wilkemann RH. Basal cell tumor with eccrine differentiation (eccrine epithelioma). Arch Dermatol. 1969;100(2):234-242.

2. Sidiropoulos M, S Sade, Al-Habeeb A, Ghazarian D. Syringoid eccrine carcinoma: a clinicopathololgical and immunohistochemical study of four cases. J Clin Pathol. 2011;64(9):788-792.

3. Whittington R, Browning ME, Farrell GR, Miremadi A. Radiation therapy and chemotherapy in malignant sweat gland tumors. J Am Acad Dermatol. 1986;15(5):1093-1097.

4. Tulenko JF, Conway H. An analysis of sweat gland tumors. Surg Gynecol Obstet. 1965;121:343-348.

5. Moy RL, Rvkin JE, Lee H, Brooks WS, Zitelli JA. Syringoid eccrine carcinoma. J Am Acad Dermatol. 1991;24(5):857-860.

6. Urso C, Bondi R, Paglierani M, Salvadori A, Anichini C, Giannini A. Carcinoma of sweat glands: report of 60 cases. Arch Pathol Lab Med. 2001;125(4):498-505.

7. Urso C, Paglierani M, Bondi R. Histologic spectrum of carcinomas with eccrine ductal differentiation (sweat-gland ductal carcinomas). Am J Dermatopathol. 1993;15(5):435-440.

8. Terushkin E, Leffell DJ, Futoryan T, Cowper S, Lazova R. Squamoid eccrine ductal carcinoma: a case report and review of the literature. Am J Dermatopathol. 2010;32(3):287-292.

9. Cooper PH, Mills SE, Leonard DD, et al. Sclerosing sweat duct (syringomatous) carcinoma. Am J Surg Pathol. 1985;9(6):422-433.

10. Sánchez NP, Winkelmann RK. Basal cell tumor with eccrine differentiation (eccrine epithelioma). J Am Acad Dermatol. 1982;6(4): 514-518.

11. Ohnishi T, Kaneko S, Egi M, Takizawa H, Watanabe S. Syringoid eccrine carcinoma: report of a case with immunohistochemical analysis of cytokeratin expression. Am J Dermatopathol. 2002;24(5): 409-413.

12. Ramos D, Monteagudo C, Carda C, Montesinos E, Ferrer J, Peydro-Olaya A. Clear cell syringoid carcinoma: an ultrastructural and immunohistochemical study. Am J Dermatopathol. 2000;22(1):60-64.

13. Nishizawa A, Nakanishi Y, Sasajima Y, Yamazaki N, Yamamoto A. Syringoid eccrine carcinoma with apparently aggressive transformation: case report and review of the literature. Int J Dermatol. 2006;45(10):1218-1221.

14. Malmusi M, Collina G. Syringoid eccrine carcinoma: a case report. Am J Dermatopathol. 1997;19(5):533-535.

15. Enomoto H, Takahashi T, Nakamura Y, Otsuka F. A case of syringoid eccrine carcinoma with circumscribed abundant stroma. J Eur Acad Dermatol Venereol. 2009;23(3):317-318.

16. Gregurek-Novak T, Talan-Hranilović J, Troskot N, Vucić M, Kruslin B. Syringoid eccrine carcinoma. J Eur Acad Dermatol Venereol. 2001;15(2):143-146.

17. Güerrissi JO, Quiroga JP. Adnexal carcinomas of the head and neck. Indian J Plast Surg. 2008;41(2):229-234.

18. Sánchez Yus E, Requena Caballero L, Garcia Salazar I, Coca Menchero S. Clear cell syringoid eccrine carcinoma. Am JDermatopathol. 1987;9(3):225-231.

19. McKee PH, Fletcher CD, Rasbridge SA. The enigmatic eccrine epithelioma (eccrine syringomatous carcinoma). Am J Dermatopathol. 1990;12(6):552-561.

20. Dahill SW, Seywright M. Synchronous occurrence of cutaneous lymphadenoma and syringoid eccrine carcinoma in a single patient. Histopathology. 1998;33(1):89-90.

21. Takata M, Hashimoto K, Mehregan P, et al. Genetic changes in sweat gland carcinomas. J Cutan Pathol. 2000;27(1):30-35. 
22. Biernat W, Peraud A, Wozniak L, Ohgaki H. p53 mutations in sweat gland carcinomas. Int J Cancer. 1998;76(3):317-320.

23. Leonard N, Chagger R, Jones C, et al. Loss of heterozygosity at cylindromatosis gene locus, CYLD, in sporadic skin adnexal tumours. J Clin Pathol. 2001;54(9):689-692.
24. Yugueros P, Kane WJ, Goellner JR. Sweat gland carcinoma: a clinicopathologic analysis of an expanded series in a single institution. Plast Reconstr Surg. 1998;102(3):705-710.

\section{Publish your work in this journal}

The International Medical Case Reports Journal is an international, peer-reviewed open-access journal publishing original case reports from all medical specialties. Previously unpublished medical posters are also accepted relating to any area of clinical or preclinical science. Submissions should not normally exceed 2,000 words or
4 published pages including figures, diagrams and references. The manuscript management system is completely online and includes a very quick and fair peer-review system, which is all easy to use. Visit $\mathrm{http}: / / \mathrm{www}$.dovepress.com/testimonials.php to read real quotes from published authors.

Submit your manuscript here: http://www.dovepress.com/international-medical-case-reports-journal-journal 